\title{
Álvaro Uribe: MÁs PATRIa QUE PUEblo. COMUNICACIÓN POLÍTICA PRESIDENCIAL en Colombia, 2002-2010
}

\author{
Jorge Iván Bonilla ${ }^{2}$ \\ Omar Rincón ${ }^{3}$ \\ Catalina Uribe $^{4}$
}

Resumen: Álvaro Uribe Vélez reinó en Colombia entre 2002 y 2010. Reinó porque siempre su popularidad fue más alta que la de cualquier telenovela o reality. Uribe gobernó comunicando: estando siempre en pantalla con emoción de melodrama y actitud de populista. En este texto se analiza la condición comunicativa que cristalizó el exitoso "pacto político" entre Uribe y los ciudadanos-feligreses de la Nación. Se examina la emergencia

1 Este trabajo forma parte de una investigación conjunta de más largo aliento realizada por los autores sobre la comunicación política gubernamental en Colombia en la última década. Aparte de este texto fueron publicados en Ponce y Rincón (2013), Entre la e-democracia, caudillismo y la tele-política, Montevideo, Universidad Católica del Uruguay. Muchos de los temas aquí planteados aparecerán en un libro de los autores que se publicará en 2014 bajo el título: De Uribe, Santos y otras especies. Agradecemos a Sonia Naranjo, del Centro de Estudios en Periodismo, Universidad de Los Andes, y a Alicia Peñaranda, del pregrado en Ciencias Políticas, Universidad EAFIT, por el trabajo de búsqueda y sistematización de la información aquí presentada.

2 Comunicador Social, Periodista, Magíster en Comunicación. Profesor Asociado del Departamento de Humanidades de la Universidad EAFIT. jbonilla@eafit.edu.co

3 Profesor asociado y director de la Maestría en Periodismo de la Universidad de los Andes, Colombia; analista de medios de El Tiempo, Colombia; consultor en comunicación para la Fundación Friedrich Ebert, Latinoamérica. orincon@uniandes.edu.co

4 Profesora Asistente del Centro de Estudios en Periodismo, Universidad de los Andes, Colombia. Magíster en Filosofía Política, Universidad de los Andes, Colombia. Es columnista del diario El Espectador. cauribe@uniandes.edu.co 
de un viejo-rural pero renovado estilo de gobernar-comunicar, basado en la promesa de volver a los valores de la autoridad, la austeridad, la disciplina y la obsesión por el trabajo, encarnados en la figura del presidente Álvaro Uribe Vélez. Por otro lado, se problematiza la consolidación de una capacidad comunicativa gubernamental que, en cabeza del jefe del Estado, combinó la política del cara-a-cara con una presencia cada vez más avasalladora en los medios de comunicación. Éstos fueron colonizados por un régimen de visibilidad presidencial que cabalgó sobre el tropos de una cultura nacional popular capaz de articular los temores e incertidumbres de amplios sectores del país en torno a un consenso de derechas que se extiende hasta nuestros días.

Palabras clave: Uribe, comunicación política, comunicación de gobierno, medios de comunicación, discurso político, populismo.

Abstract: Uribe reigned in Colombia between 2002 and 2010. He reigned because his popularity was permanently higher than that of any soap opera or reality in the history of the country. Uribe ruled communicating: always being on screen with the emotion of a melodrama and the attitude of a populist. In this text we analyze Uribe's communicative strategy, which crystallized in a successful 'political pact' between him and the citizens of the nation. By doing so, we examine the emergence of a renewed style of communicating based on the promise of the recovery of the values of authority, austerity, discipline and the obsession with work, all of them embodied in the figure of President Álvaro Uribe Vélez. Also, we contrast Uribe's ability to communicate face-to-face with the citizens with his overwhelming presence in the mass media. Television, radio and papers were colonized by a presidential communicative regime that rode on visibility 'tropes' of the popular national culture. At the end, Uribe's communication reached a righties consensus that extends to the present day.

Keywords: Uribe, political communication, government communication, media, political discourse, populism. 
"A partir de un análisis de estadística textual de discursos se evidencia que el discurso de Álvaro Uribe es monotemático y estático; niega la existencia de un conflicto armado, recurre a la luch a frontal contra el terrorismo, no cree en las ideologías, aboga por el pragmatismo y da rienda suelta al chauvinismo. Los valores tradicionales de la derecha europea como la patria, la nación, la familia, la disciplina y la autoridad son el corazón de su proyecto."

María Fernanda González, "Del uribismo popular al santismo elitista"

Cuando el 26 de mayo de 2002, Álvaro Uribe Vélez es elegido con el $53 \%$ de los votos como Presidente de la República de Colombia para el período 2002-2006, el clima de opinión en el país era bastante negativo. Según una encuesta realizada por la firma Napoleón Franco \& Cía. ${ }^{5}$ días antes de los comicios electorales, el $90 \%$ de los colombianos pensaba que las cosas en el país marchaban por un "mal camino", mientras que apenas el $20 \%$ de los encuestados tenía una imagen favorable del saliente presidente Andrés Pastrana. Al finalizar el año 2002, las cifras señalaban un cambio de opinión. El 44\% de los colombianos consideraba que las "cosas están mejorando", mientras que el índice de aprobación de la gestión del recién posesionado presidente alcanzaba el 67\%. Doce meses después, en diciembre de 2003, la popularidad de Uribe Vélez aumentaba al 78\%, según una encuesta realizada por la firma Gallup. Una frase pronto comenzó a hacer carrera como eslogan de gobernabilidad: "ahora sí tenemos Presidente". Y terminó sus ocho años de gobierno con una popularidad del $70 \%$. Rey de inicio a fin. Éxito de la comunicación y la política. Álvaro Uribe tenía un relato claro para vender a los ciudadanos:" "un país sin las FARC-EP (Fuerzas Armadas

Para consultar los resultados completos de la encuesta véase: http:// www.terra.com.co/elecciones 2002/encuestas/encuesta_9/ Recuperado el 6 de diciembre de 2011.

6 Sobre la importancia del relato en la política véase: Virgina García, Orlando D’Adamo y Gabriel Slavinsky (2005), Comunicación política y campañas 
Revolucionarias de Colombia-Ejército del Pueblo) es una Colombia feliz". Su frase de combate: "mano dura"; su horizonte de sentido: "seguridad democrática"; su ética: "todo vale para derrotar al enemigo"; su moral: "trabajar, trabajar, trabajar". Relato sencillo y potente. Y un protagonista, Uribe, quien actuó impecablemente ese relato a través de un lenguaje simple, un enemigo claro, una política de contacto con la gente, escasas entrevistas concedidas a diarios y revistas de actualidad y muchas horas dedicadas a entrevistas para la radio y para el gesto de la televisión. Relato y actuación que contaron con el apoyo irrestricto de los medios de comunicación, sobre todo RCN (radio y televisión) y El Tiempo (prensa).

En este texto se proponen tres escenarios de explicación para el éxito comunicacional de Uribe: (i) Una narrativa (re)fundacional de la Nación que instaló a partir del 7 de agosto de 2002, y cuya mejor descripción apareció en el balance del primer año de la administración Uribe, efectuado por la revista Semana: "el año en que volvió la esperanza"; (ii) La "performance mediática" de Uribe como eje del relato con el cual instaló un régimen de visibilidad basado en su personalidad y con escasa mediación periodística; (iii) La inclusión de las estéticas y expectativas del pueblo en la forma de gobernar asociada a una "política del contacto" con los colombianos de a pie y de beneficios para las élites nacionales.

electorales, Buenos Aires, Gedisa; Omar Rincón (ed.) (2008), Los telepresidentes: cerca del pueblo y lejos de la democracia, Bogotá, C3>FES; Luis Arroyo (2012), El poder político en escena, Madrid, RBA libros.

7 El objetivo de derrotar a las FARC-EP no se logró; paradójicamente la inseguridad se llevó a las ciudades y, ahora, es el Gobierno más cuestionado por corrupción, violaciones de derechos humanos y subdesarrollo de infraestructura vial del país.

8 Para consultar el texto completo del informe véase http://www.semana. com/nacion/ano-volvio-esperanza/71873-3.aspx Recuperado el 24 de noviembre de 2011 . 


\section{La narrativa fundacional: un personaje, un relato, una Nación}

La comunicación política es una lucha por el relato de la hegemonía política; y esa lucha se gana en el campo de la comunicación (Arroyo, 2012; Rincón, 2013). Esto lo entendió muy bien Álvaro Uribe, por eso cuando llegó a la presidencia estableció una misión (salvar al pueblo colombiano de la guerrilla de las FARC) que convirtió en relato único a la hora de comunicar y actuar. En consecuencia, su obsesión fue promover una nueva lectura de la reciente historia política de la nación colombiana mediante un nuevo relato fundacional que permanentemente marcaba la distinción entre un antes y un después del 7 de agosto de $2002,{ }^{9}$ y que le permitía reconstruir los referentes de interpretación del pasado histórico reciente del país y de la colombianidad misma.

Si, después de los fallidos diálogos de paz entre el Gobierno del presidente Andrés Pastrana (1998-2002) y la guerrilla de las FARC, uno de los grandes dramas de los colombianos fue la sensación de vivir en un país inviable (González, 2003), Uribe ofreció en el plano retórico un abanico de rearticulaciones posibles para volver a conectar la acción individual y el sentido colectivo de la Nación (Pecaut, 2003). Por eso no es gratuito que a partir de 2002 comenzaran a circular una serie de narrativas -en boca de muchos colombianos, no sólo del Presidente- dirigidas a ocupar el lugar vacío dejado por la angustia, la incertidumbre y la impotencia del fracasado proceso de paz y la crisis financiera de finales del siglo $\mathrm{XX}$, y entre cuyas frases más representativas estaba la siguiente: "Ahora sí podemos viajar por las carreteras del país".

Fecha en la que se posesionó como Presidente de la República de Colombia. 
Ahora bien, como Uribe fue elegido Presidente para liquidar con la guerrilla, salvar a una Nación que se encontraba desesperanzada (Rincón, 2002) y recuperar la confianza en las instituciones, su plan bandera se constituyó en torno a un relato unificador: la seguridad democrática. Este plan, junto con su famoso lema de campaña "mano firme, corazón grande", partía de tres puntos claves expuestos en su plan de gobierno: ${ }^{10}$

1. "Recuperar la confianza inversionista en Colombia con orden público, buen manejo macroeconómico, claridad y estabilidad en las reglas de juego. Controlaremos el lavado de activos para que el dólar barato no siga arruinando nuestra producción. Con el fondo de garantías, estímulos tributarios, premios al pago puntual, créditos asociativos y préstamos a través de fundaciones. Habrá una tasa de interés más razonable. Si una exención tributaria se elimina antes de tiempo, que el Estado indemnice a los afectados para que haya confianza inversionista. Sin corrupción ni politiquería los recursos tienen que alcanzar para erradicar la miseria y construir justicia social." ${ }^{11}$

2. "Colombia sin guerrilla y sin paramilitares. La autoridad legítima del Estado protege a los ciudadanos y disuade a los violentos. Es la garantía de la seguridad ciudadana durante el conflicto y después de alcanzar la paz." 12

Tomado del programa oficial de gobierno del presidente Álvaro Uribe, 2002-2006: "Mano firme, corazón grande. El camino de la confianza". Recuperado el 24 de noviembre de 2011 de http://www.colombia.com/ especiales/elecciones_2002/planes/uribe/

11 La confianza inversionista funcionó en cuanto a privilegios fiscales para los inversores extranjeros y los empresarios colombianos, pero el dólar siguió barato y la corrupción y la politiquería siguieron en aumento. Pero a los empresarios les fue bien. Ésa era realmente la promesa.

12 La idea de un país sin guerrilla fue el gran relato del Gobierno y se comunicó como su gran éxito. 
3. “Enalteceré la profesión de soldado y policía. Que la comunidad los valore y respete. Que ellos se esmeren por merecer respeto y admiración. Que reciban formación técnica y su esfuerzo sea premiado con becas de estudio y altas calificaciones. Con más policías y soldados nuestra fuerza pública sufrirá menos bajas, será más respetada y el pueblo vivirá más tranquilo." ${ }^{13}$

En esta narrativa (re)fundacional de la historia reciente de la Nación, Uribe explotó además el relato del colombiano rural que, en conexión con el pueblo de verdad, se hace a sí mismo, un self-made man a la colombiana, es decir, el hombre hecho a "puro pulso" que surge gracias al esfuerzo, el trabajo y sus valores. La suya era una narrativa que pretendía hablar en nombre de los sectores católicos, rurales y trabajadores con los cuales se identifica buena parte de la Nación colombiana; de ahí que constantemente proyectara una imagen de mandatario en permanente contacto con el pueblo (De la Torre, 2005): un hombre popular sin vergüenza de ser rural, lo cual explicaba sus constantes alusiones críticas y despectivas contra las élites bogotanas, a quienes acusaba de ser hipócritas, tomar whisky en fiestas anodinas y hablar mal de los demás, mientras él sólo se dedicaba a "trabajar, trabajar y trabajar". ${ }^{14}$ El ex columnista del

13 Otro éxito de relato y ejecución.

14 Esta frase, que se convirtió durante ocho años en un eslogan del Gobierno, fue pronunciada por primera vez el 5 de febrero de 2002 en una rueda de prensa improvisada ante periodistas; así respondió Álvaro Uribe a la pregunta de un periodista sobre qué iba a hacer ahora que encabezaba, según las encuestas electorales, la intención de voto de los colombianos: "trabajar, trabajar y trabajar", dijo. 
diario El Espectador y filósofo Rodolfo Arango ${ }^{15}$ define su imagen de la siguiente manera:

Utilizaba un lenguaje para acercarse el pueblo; era meloso y caritativo. El gran padre de familia del pueblo colombiano. Un gran demagogo, un gran comunicador de masas, un hombre muy hábil en el discurso que explota los sentimientos de la población. El típico caso de resentimiento hacia las élites, hacia los ricos; él, siendo una persona millonaria, se presenta como un hombre trabajador, y en ese sentido se convierte en una figura muy popular del pueblo colombiano.

Para este hombre rural, trabajador y católico, que además amaba a su país, los símbolos patrios eran la vía para conectarse con la Nación; por eso también se preocupó por desatar un sistema narrativo (discursos + gestos + dramatizaciones + temporalidades + rituales) dirigido a generar un patriotismo y un nacionalismo exacerbados, importantes en el proyecto de reinvención de la patria a través del orden que da la seguridad democrática y el valor que asignan la religión católica y la familia. Este nacionalismo lo proyectó mostrándose cercano a la gente y poniendo al pueblo como luz de pensamiento. Lo anterior lo logró mediante una narrativa política que se supo ubicar en la intersección entre un sistema de creencias ideológicas y un sistema de pasiones políticas como la ruta más apropiada para generar un consenso favorable en la opinión pública ${ }^{16}$

15 Entrevista realizada en agosto de 2011.

16 Esto, por supuesto, nos obliga a considerar que la opinión pública no es sólo el ámbito del uso público de la razón, sino también el de la pasión, esto es, el campo de las creencias, las experiencias personales y compartidas, las adhesiones, los rechazos, las memorias, los amores y los odios que se expresan a través de discursos y relatos que no necesariamente llevan el sello de la "irracionalidad". Es justamente allí donde era fuerte la narrativa presidencial. Un texto clave para este tipo de análisis: Lucrecia 
nacional (Bonilla, 2004). De ahí que la fuerza discursiva de Uribe radicara en su capacidad para producir un efecto de sentido melodramático, que era reconocido como verdadero por amplios sectores de la población colombiana, y en su capital simbólico de afectos, emociones y creencias. Uribe efectivamente vino a "ofrecer su corazón" a los colombianos, y nos hizo parte de su misión, de su familia, de su lucha.

Para el analista en comunicación política Álvaro Forero, ${ }^{17}$ lo anterior se explica porque Uribe practicaba la tesis de que las personas no se acuerdan de lo que dice el político sino de cómo las hace sentir. Y es que el ciudadano común no habla en términos de razones sino de percepciones emocionales: "Uribe es uno de nosotros". Es por esto que siempre trató de mostrarle a la gente que él estaba a cargo de todos los problemas y que él los iba a solucionar. La mayoría de las decisiones las tomaba él, mientras que a su gabinete de Gobierno le correspondía el papel de coro dramático. En otras palabras, no tenía interlocutores sino subordinados. Elber Gutiérrez, ${ }^{18}$ editor político de El Espectador, lo describe de la siguiente manera:

Uribe era el Presidente, pero al mismo tiempo era el ministro, el viceministro, el secretario del viceministro; entonces Uribe era todo, quería tener el control de todos los temas, con lo bueno y lo malo que eso pueda tener.

Al personificar al pueblo, a la patria y al Estado, Uribe se convirtió en el Gobierno mismo. Él era toda la performance del Gobierno y de Colombia. En su narrativa de (re)fundación de la Nación, asumió que los colombianos

Escudero (2002), “Un sujeto patémico: los desaparecidos en la prensa argentina”, DeSignis, 2, pp. 187-201.

$17 \quad$ Entrevista realizada en agosto de 2011.

18 Entrevista realizada en agosto de 2011. 
entendíamos la lealtad a las personas más que a las ideas o a las instituciones: así, lo que importaba era que Él nos amaba y nosotros lo amábamos a él. Por ello, a todo le dio una narrativa sencilla y una gestualidad de fácil acceso: hablar como el pueblo, vestirse con la iconografía del pueblo y apelar al capital simbólico de naturaleza religiosa y familiar al que todavía apela buena parte de este país.

No basta con tener un relato sino que hay que actuarlo y encarnarlo (Arroyo, 2012). Uribe construyó varios personajes en uno solo para generar confianza en los ciudadanos: un líder a quien seguir; un motivador a quien admirar; un patrón a quien obedecer; un maestro de quien aprender; un padre regañón a quién amar (Rincón, 2008). De ahí que fuera percibido como un hombre visceral, emotivo, sincero y real, aunque detrás de eso se escondiera un político tremendamente racional, calculador y frío. En política, la comunicación es la acción pública y lo racional forma parte del diseño de la acción de poder. Así, mientras su estrategia comunicativa se basaba en plantear un radicalismo irreconciliable entre buenos y malos, su cálculo político se consolidaba en la negociación.

El investigador Carlos Mario Perea (1996) proporciona algunas pistas para comprender el radicalismo retórico de Uribe cuando habla del "gesto de enfrentamiento", término utilizado para estudiar el "pacto" de destrucción verbal mediante el cual los partidos liberal y conservador justificaron la eliminación sistemática del Otro durante la mitad del siglo XX en Colombia. Para Perea, lo que explicaba el enfrentamiento entre liberales y conservadores no era el hecho de que persiguieran proyectos políticos antagónicos, ya que ambos partidos políticos tenían más convergencias que diferencias en cuanto al campo social, la cuestión religiosa y la política económica. El "gesto de enfrentamiento", como una 
dimensión que conectaba lo simbólico con lo político, obedecía más bien a una fundamentación abstracta de lo político que operaba sobre la base de un sistema compartido de significaciones desde el que se establecían -y se apelaba a- estados de ánimo, motivaciones, creencias $\mathrm{y}$ sentimientos en las poblaciones adherentes a uno $\mathrm{u}$ otro sistema de sentido: era una cuestión más de sangre o de herencia o de religión que de ideología.

Guardadas las proporciones, el núcleo de sentido para entender la cruzada narrativa de Uribe por definir un antes y un después de la patria y por demarcarle al ciudadano común cuál posición política ${ }^{19}$ debía adoptar en la experiencia de vivir cotidianamente la Nación (“¿Sabe usted de qué lado está?") radicó justamente en esta fundamentación tradicional de lo político colombiano: pegado a herencias más que a ideas. Ahí estaba su fuerza. La "idea uribista" no admitía incrédulos: para saber, había primero que creer. La suya era, por lo tanto, una narrativa de naturaleza religiosa: una idea, un sentimiento, una moral, un mesías, un espíritu, un ciudadano-creyente. Así, lo que la narrativa de Uribe realizó con éxito fue encausar a la patria, como la familia de los colombianos, en una misión: asumir que las FARC eran el enemigo central de los colombianos y que todos aquellos que no compartían esta misión eran pecadoresterroristas-apátridas: "estás conmigo o estás contra mí".

\footnotetext{
19 Y no ideológica, ya que Uribe mismo había definido que sólo había una, y que todo lo demás era terrorista.
} 


\section{La mediática Uribe: un Presidente que hablaba demasiado}

Como hemos visto, con Álvaro Uribe se inaugura en Colombia el tiempo de las esperanzas crecientes, esto es, el de la credibilidad en un líder que durante ocho años puso en marcha un sistema de actuaciones, adhesiones, pasiones y sentimientos en la formación de la opinión pública colombiana. Con él también se cristaliza una renovada época de asunción de la comunicación presidencial, a medio camino entre las modernas estrategias del marketing de Gobierno y las viejas técnicas de la propaganda y la persuasión política. ${ }^{20}$ La contundencia, la verticalidad y la eficacia de la actuación mediática de Uribe apuntaban a un objetivo central: a que él fuera el emisor de su propia comunicación, eliminando intermediarios y creando espacios de comunicación directa con la Nación. Muy a lo popular: más que espectadores, vivencia de la gobernabilidad.

Uribe era un presidente que hablaba demasiado: 296 entrevistas en ocho años (37 por año) y de las cuales el $78 \%$ fueron para la radio; tomar el habla del pueblo: la palabra escrita queda, la palabra oral se la lleva el viento; la escrita aleja, la oral acerca. La fascinación de Uribe por la radio está en que el mensaje presidencial tenía la fuerza del mensaje directo; le permitía explayarse en sus mensajes, mostrar sus fortalezas retóricas y modular los tonos discursivos; allí los periodistas no editaban sus respuestas, como sí lo hacían en la prensa o en la televisión; la radio le permitía,

20 Para analizar la performance de Uribe sería muy útil volver sobre las cinco reglas de la propaganda política expuestas por Jean Marie Domenach: i) Regla de la simplificación y del enemigo único; ii) Regla de la exageración y desfiguración; iii) Regla de la orquestación; iv) Regla de la transfusión; v) Regla de la unanimidad y el contagio. Véase Jean Domenach (1963), La propaganda política, Buenos Aires, Eudeba. 
además, replicar y convertirse, él mismo, en entrevistador, conductor, moderador. La otra razón apunta a que en Colombia la radio ha cumplido un importante rol en la integración nacional y la cohesión social, no sólo por la definición de agenda noticiosa que provee, sino porque la radio es el medio más cercano a la cultura popular nacional del país. Más que un telepresidente (Rincón, 2008), Uribe era un radiopresidente, esto es, un hombre que en la radio desplegaba toda su capacidad de persuasión política por la vía de la retórica y la oralidad. Desde allí, Uribe creó la representación teatral de un colombiano cercano-localregional: trabajador, madrugador y creyente. Un ciudadano hijo de la oralidad de la radio, de la oralidad de la Nación.

Uribe, así, se encargó de ser él mismo la noticia ${ }^{21}$ y actuaba con un papel diferente para cada medio: en la radio era el hombre del pueblo que estaba con el pueblo en tiempo real (en ocho años, concedió 230 entrevistas radiales); en la televisión creó un formato propio llamado "consejos comunales de gobierno", con el cual él y la televisión iban a los pueblos olvidados de la geografía política y gobernaban en vivo y en directo (realizó 276 consejos comunitarios a lo largo y ancho del país); a los principales medios escritos del país los atendía a cuenta gotas y sólo para establecer la agenda de temas a debatir (de las 23 entrevistas que concedió a medios escritos, sólo 9 fueron para la "gran prensa" y 2 para revistas de actualidad noticiosa).

21 Catalina Montoya (2007) en su trabajo de grado de la Maestría en Ciencia Política de la Universidad de Antioquia documenta cómo durante 2005 la noticia política privilegiada de la televisión era Uribe, y anota un detalle interesante: mientras el Canal RCN lo narraba como una celebrity (alguien que todo lo que toca lo convierte en éxito), Caracol Noticias lo relataba como un héroe agonal: alguien que abre puertas, crea caminos, imagina futuros. Y estos dos canales son el $90 \%$ del rating televisivo del país. Uribe, el héroe. 
Tabla 1

Entrevistas concedidas por Álvaro Uribe a medios de comunicación, 2002-2010

\begin{tabular}{|l|c|c|c|c|c|c|c|c|c|c|}
\hline \multirow{2}{*}{$\begin{array}{c}\text { Tipo de } \\
\text { medio }\end{array}$} & \multicolumn{10}{|c|}{ Número de entrevistas concedidas por año } \\
\cline { 2 - 13 } & $\mathbf{2 0 0 2}$ & $\mathbf{2 0 0 3}$ & $\mathbf{2 0 0 4}$ & $\mathbf{2 0 0 5}$ & $\mathbf{2 0 0 6}$ & $\mathbf{2 0 0 7}$ & $\mathbf{2 0 0 8}$ & $\mathbf{2 0 0 9}$ & $\mathbf{2 0 1 0}$ & Total \\
\hline Prensa & 1 & 2 & 4 & 1 & 3 & 6 & 4 & 1 & 1 & 23 \\
\hline $\begin{array}{l}\text { Revistas de } \\
\text { actualidad }\end{array}$ & 0 & 1 & 0 & 0 & 1 & 0 & 0 & 0 & 0 & 2 \\
\hline Radio & 0 & 10 & 13 & 16 & 20 & 41 & 17 & 14 & 99 & 230 \\
\hline Televisión & 1 & 5 & 1 & 8 & 6 & 4 & 1 & 2 & 7 & 35 \\
\hline $\begin{array}{l}\text { Agencia de } \\
\text { prensa }\end{array}$ & 0 & 0 & 0 & 0 & 0 & 1 & 0 & 1 & 0 & 2 \\
\hline $\begin{array}{l}\text { Portales de } \\
\text { internet }\end{array}$ & 0 & 0 & 0 & 0 & 0 & 2 & 0 & 1 & 0 & 3 \\
\hline $\begin{array}{l}\text { Diarios on } \\
\text { line }\end{array}$ & 0 & 0 & 0 & 1 & 0 & 0 & 0 & 0 & 0 & 1 \\
\hline Total & 2 & 18 & 18 & 26 & 30 & 54 & 22 & 19 & 107 & 296 \\
\hline
\end{tabular}

Fuente: Elaboración propia con información suministrada por el portal web de la Presidencia de la República de Colombia

Un enemigo: las FARC; una actuación: un país que reinventa la patria; un héroe: un Presidente salvador, pacificador combativo y ciudadano enamorado de la patria. Y todo actuado en los medios de comunicación. Mucho de espontaneidad y autenticidad del personaje (Uribe) y mucho de estratega de marketing. En el marketing siguió las recomendaciones de los estrategas de la persuasión política (Hovland, Janis y Kelley, 1953; Maarek, 1996; Morris, 1999; Gergen, 2000; Arroyo, 2012) que recomiendan mostrar liderazgo, movilizar confianza, generar credibilidad, dar la cara a los problemas, producir resultados, medir la opinión pública de manera constante y mantenerse en campaña permanente, pero mezclando todo esto con las viejas técnicas de la retórica (Aristóteles, siglo IV a. C.) y 
la propaganda política (Merton, 1949; Domenach, 1963; Bobbio y Matteucci, 1982) que proponen simplificar el mensaje, crear un enemigo que genere consensos en la población, desdeñar al adversario, apoyarse en los hechos, hablar en el lenguaje de las mayorías, disponer favorablemente al destinatario, explotar las pasiones del oyente y repetir hasta el cansancio.

Jaime Bermúdez, su consejero de comunicaciones (2002-2006) y luego su ministro de Relaciones Exteriores (2008-2010), resume el secreto de la buena imagen de Uribe en cuatro aspectos fundamentales: ${ }^{22}$

1. Tiene visión, es decir, tiene claro a dónde quiere llevar el país y lo ha comunicado bien.

2. Tiene un gobierno orientado a resultados, a mostrar resultados concretos, y ha llevado a que haya victorias tempranas, que es fundamental para que la gente vea que hay transformaciones inmediatas, no a largo plazo.

3. La manera como se relaciona con la gente, vía consejos comunales que son reuniones que hace todos los fines de semana por todo el país, abierto, con toda la comunidad: las fuerzas vivas, los gobernadores, los alcaldes. Con una agenda, pero sin veto a ninguna palabra. Primero el gobierno nacional presenta algunos temas fundamentales, después los gobiernos locales hacen sus presentaciones, después la comunidad participa, le pregunta al presidente, y el presidente hace unos comentarios... o da instrucciones... lo que él pueda ir resolviendo en el camino.

22 Este resumen de la buena imagen de Uribe lo hace Jaime Bermúdez en una entrevista para un canal de televisión argentino. Véase la entrevista completa en http://www.youtube.com/watch?v=oqgiqyJv-3E Recuperado el 6 de diciembre de 2011. Jaime Bermudez tiene un interesante trabajo comparativo sobre la comunicación política en Colombia y Venezuela entre 1994 y 1998. Véase Bermudez, 1999. 
4. Cuando hay crisis pone la cara, enfrenta la crisis. No deja que sean otros lo que hablen de eso. Se va donde está la crisis.

En el propósito de ser el emisor de su propia comunicación, un punto fundamental en el Gobierno de Uribe fue el hecho de que los medios y los periodistas diluyeron su rol de mediadores de la palabra pública en favor del protagonismo presidencial. Para lograrlo, el equipo de comunicaciones de la Casa de Nariño decidió restringirle al mainstream mediático nacional el acceso privilegiado que éste tenía con respecto al manejo de la información política, por lo que el Presidente comenzó a hablarles a los ciudadanos directamente a través de una renovada estrategia de comunicación que no se basaba ni en las tradicionales alocuciones presidenciales (en ocho años, Uribe hizo 38 alocuciones), ni las recurrentes conferencias de prensa (31 durante su Gobierno). Siguiendo a la periodista Luz María Sierra (2011) podemos sintetizar este punto en cinco aspectos fundamentales:

1. El presidente montó una agencia de noticias utilizando a las emisoras locales como canales para transmitir la información. Antes la información que producía la presidencia sólo les llegaba a 50 medios de comunicación; con Uribe (más la nueva tecnología de Internet y los mensajes de celular) más de 3000 medios recibían la información proveniente de la Casa de Nariño. Y como en el Gobierno de Uribe la información se enviaba como noticia de agencia y no como comunicado de prensa, los medios leían la información tal cual estaba redactada (Sierra, 2011). Las apariciones en los medios fueron constantes: en 2005 la mitad de los titulares los ocupaba Uribe (47\%) y la mayoría de las noticias (65\%) eran noticias programadas por la Casa de Nariño (Montoya, 2007). 
2. El presidente daba entrevistas permanentemente a radios locales. Durante su Gobierno se puso como tarea hablar con emisoras distintas; en temporada electoral les dedicaba de cuarenta y cinco minutos a una hora y media. Ello tuvo algunas características: i) Casi siempre las entrevistas se hacían por solicitud de la Casa de Nariño; ii) El presidente sólo contestaba las preguntas que él decidía y para el resto eludía la respuesta (Sierra, 2011).

3. La presidencia produjo contenido para medios en crisis. La estrategia de comunicación indicaba que la oficina de prensa a través del Presidente y de los ministros les ponía la agenda a los medios masivos: si un tema estaba afectando la popularidad del Presidente proponían varios escándalos alternos o el Presidente introducía un nuevo tema polémico (Sierra, 2011).

4. Limitó los medios impresos y extranjeros. Uribe no le apuntó a los medios impresos porque no le gustaba la manera en la que ellos editaban y titulaban; por tal motivo, le dio preponderancia a la televisión y a la radio. Como bien lo afirman Miguel García y Laura Wills, los eslóganes como "trabajar, trabajar, trabajar", "seguridad democrática" y "confianza inversionista" encontraron en la televisión un medio de canalización privilegiado para los propósitos de comunicación política de Uribe. A esto se le sumó que los escándalos fueron publicados principalmente por medios escritos (García y Wills, 2011).

5. Los consejos comunales. Los consejos comunales fueron programas (Talk shows) en los que la gente común, los gobernantes locales y los políticos de provincia iban a contarle sus penas al presidente Uribe, que dejaba de ser el Presidente para convertirse en una especie de presentador de televisión (Rincón, 2005). Durante 276 sábados, el Presidente estuvo en vivo y 
en directo ante el país desde las 8 de la mañana hasta las 6 de la tarde en promedio. Así, durante esta puesta en escena del primer mandatario, los colombianos creíamos que nuestro Presidente nos estaba resolviendo los problemas. Él mismo ejercía como maestro de ceremonia y moderador para dar la palabra. Durante los consejos comunales se veían situaciones en las que Uribe entregaba cheques para públicos beneficiarios de los programas del Gobierno, asignaba recursos, regañaba a sus ministros, insultaba a la oposición, daba su teléfono celular en vivo y en directo para que los compatriotas de la patria lo llamaran y ordenaba a la policía que metiera en la cárcel a funcionarios bajo sospecha.

En tanto que Presidente exitoso, Uribe le impuso la agenda al país (Sierra, 2011; García y Wills, 2011). Tuvo una exacerbada habilidad comunicativa para producir los titulares y definir la situación mediáticamente a su favor, de modo que los medios no tuviesen mucha alternativa a la hora de ser críticos. La mayoría de éstos se alinearon y le hicieron el juego a la mediática de Uribe que, como gran comunicador, pretendía llegarles directamente a los ciudadanos: decía lo que la gente quería oír, tenía la agenda copada, no dejaba espacios y, cuando se le controvertía -situación que rara vez ocurría- no solía responder con argumentos sino con adjetivos descalificadores contra los medios, los periodistas y los sectores de oposición, ${ }^{23}$ lo que, por cierto, generaba titulares.

23 La lógica mediática de Uribe se puede describir como: (i) periodista y medio denuncian que hay corrupción en X contrato del Gobierno; (ii) medios televisivos y afines al Gobierno no dan cuenta de la denuncia pero sí de la posición del Gobierno; (iii) el Presidente y sus voceros atacan y denigran con adjetivos a quien informa o critica; (iv) el Presidente nunca responde a la acusación realizada; (v) se propone una agenda alterna. La fórmula es desprestigiar a quien relata y no preocuparse por lo que se relata. 
Esto, por supuesto, iba acompañado de una paradoja: aunque Uribe actuaba diariamente en los medios, tenía un gran desdén por la función periodística de la mediación, la que buscaba sustituir hablándole directamente a la Nación. Esto fue precisamente lo que se pudo observar en sus respuestas a la entrevista que el corresponsal de la cadena británica BBC Mundo ${ }^{24}$ le hiciera en mayo de 2009, en un momento en que se vivía un clima de incertidumbre en torno a las intenciones de reelección del presidente Uribe:

Periodista: Hay una pregunta sobre la situación política de Colombia... Hay una pregunta que no puedo evitar hacerle, ¿usted quiere ser presidente de Colombia cuatro años más? Presidente Uribe: Otra pegunta amigo... ¿ ¿usted dónde nació? Periodista: Yo soy argentino.

Presidente Uribe: Estudie la historia de su país... deje la democracia colombiana tranquilita. Otra pregunta.

Periodista: Creo que es una pregunta válida...

Presidente Uribe: Otra... otra pregunta.

Periodista: Hay todo un proceso...

Presidente Uribe: Otra pregunta.

Periodista: Si me permite realizarle la pregunta... luego usted verá si la responde...

\section{Presidente Uribe: Claro...}

Periodista: Hay todo un proceso en marcha en Colombia por convocar un referendo para permitir que usted sea reelecto... ¿Usted cuándo planea pronunciarse sobre el tema, tiene decidido presentarse o no?

Presidente Uribe: Me da la oportunidad de decir lo siguiente. Por eso científicos de la política recomiendan que en la política es mejor entenderse directamente con la opinión pública que hacerlo con quienes pretenden ser los voceros de la opinión, porque muchas veces quienes pretenden ser voceros de la opinión no la interpretan...

Periodista: Pero es que la opinión pública...

24 Véase la versión completa de la entrevista en: http://www.bbc.co.uk/ mundo/america_latina/2009/05/0905041210_uribe_entrevista_jm.shtml Recuperado el 24 de noviembre de 2011. 
Presidente Uribe: Déjeme, yo le dejé hacer la pregunta... sino que simplemente se dejan llevar por los sesgos. Entonces usted me da la oportunidad de hacer la campaña que quiero hacer y que pienso es conveniente para Colombia. Pertenezco a una generación que no ha vivido un día completo en paz, por eso mi campaña es una: Colombia necesita prolongar en el tiempo la seguridad democrática, después de que vivimos 60 años de violencia; la confianza inversionista después de que por décadas vimos que crecía enormemente la población y se estancaba la inversión; y la cohesión social, después de que durante muchas campañas políticas asistimos a propuestas de mejoramiento social que no se traducían en hechos...

Periodista: Usted me habla de ideas y de un proyecto de país que usted tiene, y me dice que a usted le gusta relacionarse directamente con la opinión pública evitando los voceros... Presidente Uribe: Así es...

Periodista: La opinión pública en Colombia también se está preguntando si usted quiere ser presidente de nuevo... Presidente Uribe: Deje... deje a los colombianos... ¿ ¿cuánto hace que usted no va a Colombia?

Periodista: No tengo el placer de conocer Colombia.

Presidente Uribe: Vaya...

Periodista: Pero seguimos de cerca... mi trabajo es seguir las relaciones internacionales...

Presidente Uribe: Demórese un poquito en Colombia.

A pesar de que la mayoría de las empresas periodísticas adhirieron a la misión de Uribe y de que el periodismo perdió independencia, algunos medios de comunicación (Semana, Cambio, El Espectador, Caracol Radio y Noticias Uno), varios periodistas (Daniel Coronell y su equipo periodístico; Alejandro Santos y su equipo; Fidel Cano y su equipo; Hollman Morris y su equipo) y distintos columnistas de prensa (María Jimena Duzán, Ramiro Bejarano, Felipe Zuleta, Claudia López, entre otros) se convirtieron en el lugar del disenso y la denuncia de las agendas del Gobierno, y así lograron pegar en la opinión pública sonados 
escándalos relacionados con la corrupción, la politiquería, la desidia gubernamental frente a los derechos humanos y la desinstitucionalización democrática. Estos medios, periodistas y columnistas reivindicaron la función crítica del periodismo al informar o denunciar las anomalías del Gobierno, ya fuera con base en su trabajo de reporteros y en su investigación periodística, o gracias a las filtraciones de documentos provenientes de fuentes interesadas.

Un caso paradigmático fue el del periodista Daniel Coronell, quien en su columna de la revista Semana ${ }^{25}$ y en su noticiero de televisión Noticias Uno denunció, con base en una información publicada el 15 de junio de 1983 por el diario El Mundo, el préstamo de un helicóptero de propiedad del narcotraficante Pablo Escobar al entonces ex alcalde de Medellín Álvaro Uribe Vélez para rescatar el cuerpo de su padre asesinado por las FARC en jurisdicción del municipio de Yolombo, Antioquia. ${ }^{26}$ Este hecho produjo una fuerte reacción del presidente Uribe, quien el 9 de octubre de 2007, en la emisora La FM de RCN y durante más de 30 minutos, se tranzó en una agria disputa con Coronell transmitida en directo para todo el país: ${ }^{27}$

Presidente Uribe: ¡Es mentira! ¡Es mentira!, usted está mintiendo. Si yo, mire, en medio del dolor, del desespero, si a uno le dicen que se está montando en un helicóptero de Pablo Escobar, no se monta... ¡no me calumnie! Yo he procedido hoy con toda la franqueza pero con toda la tranquilidad, una

El artículo titulado "Los de las gafas" puede consultarse en http:// www.semana.com/opinion/gafas/106703-3.aspx Recuperado el 24 de noviembre de 2011.

26 Este hecho es la base fundamental del odio de Uribe hacia las FARC, ya que asesinaron a su padre. La derrota de esta guerrilla es una venganza personal, que ahora es la lucha de toda una Nación.

$27 \quad$ Para ver el texto completo de la disputa radial entre el presidente Uribe y el periodista Daniel Coronell puede consultarse: http://es.scribd. com/doc/46516053/Entrevista-Rcn-Uribe-Coronell Recuperado el 24 de noviembre de 2011 . 
cosa es el valor civil y otra cosa es la cólera. Mire: para que de una vez le quede claro, como lo he dicho tantas veces de mi vida, en tantas ocasiones de mi vida, ninguna relación tuve con Pablo Escobar; como lo dije en esa campaña de 2002: no fui amigo de Pablo Escobar ni cuando estaba de moda. Y hágame un favor, aclare un hecho: ¿cuáles son los allegados míos que atentaron contra usted?

Daniel Coronell: Señor Presidente, eso está perfectamente claro y yo lo denuncié públicamente en su momento... (cortado abruptamente por el Presidente).

Presidente Uribe: No, Dígalo. No deje... (cortado por el periodista Coronell).

Daniel Coronell: Usted jamás le ha explicado al país su relación con el señor Carlos Náder Simmonds, narcotraficante condenado en Estados Unidos... (cortado abruptamente por el Presidente).

Presidente Uribe: Se la explico claramente, para que deje usted de tejer, de tejer donde no se debe tejer, para que deje usted de buscar calumnia y maledicencia. Yo conocía Carlos Náder Simmonds en las campañas del Presidente López Michelsen. Daniel Coronell: ¿Antes de haber estado preso por narcotráfico?

Presidente Uribe: Antes de haber estado preso por narcotráfico (cortado abruptamente por Coronell).

Daniel Coronell: Señor Presidente: ¿después de esa condena por narcotráfico, a usted le parece que sigue siendo ésa una compañía recomendable para el Presidente de la República de Colombia y para su familia?

Presidente Uribe: Espere le digo; espere le digo, señor Coronell, porque usted maltrató a mis hijos. Usted los calumnió... (cortado abruptamente por Coronell).

Daniel Coronell: ¡No, señor! (cortado abruptamente por el Presidente)

Presidente Uribe: ¡Usted los calumnió! Escúcheme... (cortado abruptamente por Coronell).

Daniel Coronell: Yo no he mencionado... (cortado abruptamente por el Presidente).

Presidente Uribe: ¡Escúcheme! (cortado abruptamente por Coronell). 
Hay que reivindicar el papel histórico de los periodistas y los medios que mantuvieron cierto espíritu crítico frente a la máquina de comunicar que era Uribe. Sin ellos, el relato hegemónico de Uribe hubiese sido asumido como única verdad, que recibía legitimidad por la actuación pública del Presidente. Los escándalos denunciados siguen atormentando a líder pero no rebajan su popularidad: su actuación es muy convincente, tanto como para creer en su palabra más que en los hechos denunciados.

\section{Cuando gobernar es estar ahí: Uribe o la política del contacto}

Uribe gobernó en vivo y en directo: siempre en contacto con el pueblo, con los empresarios, con los políticos, con los medios locales. Una parte esencial -otra más- de su estrategia comunicativa era pronunciar discursos en la inauguración de obras de infraestructura física; en el lanzamiento de programas de Gobierno; o en la instalación o clausura de eventos empresariales, gremiales, religiosos, sociales, deportivos y culturales, para desde allí generar noticia y mostrarse cercano a los diversos sectores sociales. En ocho años de Gobierno pronunció 1982 discursos (además de las 296 entrevistas que dio, de las 38 conferencias de prensa que ofreció, de las 31 alocuciones presidenciales que realizó y de los 276 consejos comunales de gobierno que condujo). No importaba el tema o el evento, el discurso era generalmente el mismo, sobre todo a partir de su segundo período presidencial (2006-2010): la "seguridad democrática", que se traducía en la lucha contra el terrorismo, era el camino para generar la "confianza de los inversionistas", lo que a su vez traería paz, prosperidad y "cohesión social" para los colombianos. Un relato hegemónico bien construido y mejor comunicado. 
Tabla 2

La comunicación política de Álvaro Uribe, 2002-2010

\begin{tabular}{|l|c|c|c|c|c|c|c|c|c|c|}
\hline \multirow{2}{*}{$\begin{array}{c}\text { Tipo de } \\
\text { comunicación }\end{array}$} & \multicolumn{10}{|c|}{ Año } \\
\cline { 2 - 12 } & $\mathbf{2 0 0 2}$ & $\mathbf{2 0 0 3}$ & $\mathbf{2 0 0 4}$ & $\mathbf{2 0 0 5}$ & $\mathbf{2 0 0 6}$ & $\mathbf{2 0 0 7}$ & $\mathbf{2 0 0 8}$ & $\mathbf{2 0 0 9}$ & $\mathbf{2 0 1 0}$ & Total \\
\hline Alocuciones & 1 & 6 & 5 & 2 & 2 & 4 & 11 & 4 & 4 & 31 \\
\hline $\begin{array}{l}\text { Conferencias } \\
\text { de prensa }\end{array}$ & & & 1 & 1 & 1 & 3 & 10 & 9 & 5 & 38 \\
\hline $\begin{array}{l}\text { Consejos } \\
\text { comunales }\end{array}$ & 15 & 38 & 31 & 37 & 26 & 37 & 30 & 32 & 30 & 276 \\
\hline Entrevistas & 2 & 18 & 18 & 26 & 30 & 54 & 22 & 19 & 107 & 296 \\
\hline Discursos & 69 & 234 & 298 & 253 & 229 & 205 & 212 & 296 & 186 & 1982 \\
\hline
\end{tabular}

Fuente: Elaboración propia con información suministrada por el portal web de la Presidencia de la República de Colombia

¿Cuáles eran los motivos de esos discursos, quiénes eran sus públicos más frecuentes y de qué temas hablaba el presidente Uribe? En cuanto a lo primero, al revisar las motivaciones por las que el mandatario pronunciaba sus discursos se encuentra que el $22 \%$ era en la instalación y clausura de eventos, el $21 \%$ en visitas y reuniones, el $13 \%$ en conmemoraciones y celebraciones, y el $12 \%$ en homenajes, premios y condecoraciones, es decir, se trataba de motivaciones en las que primaba un acercamiento al ethos nacional, certámenes que apuntaban a reforzar los rituales cívicos de la Nación.

Además, la fuerza narrativa de Uribe no descansaba únicamente en la mediación tecnológica de los medios, sino en la combinación de lo mediático con lo presencial: allí estaba el presidente Uribe y, por supuesto, las cámaras de televisión detrás de él, con lo que se aseguraba no sólo hablarle a distancia al "gran público" de la Nación, sino a públicos presenciales en tiempo real que más tarde compartirían con sus amigos y familiares la noticia de haber visto al Presidente en persona. 
Gráfico 1: Entrega de subsidios y programas de gobierno Motivos de los discursos presidenciales de Álvaro Uribe, 2002-2010

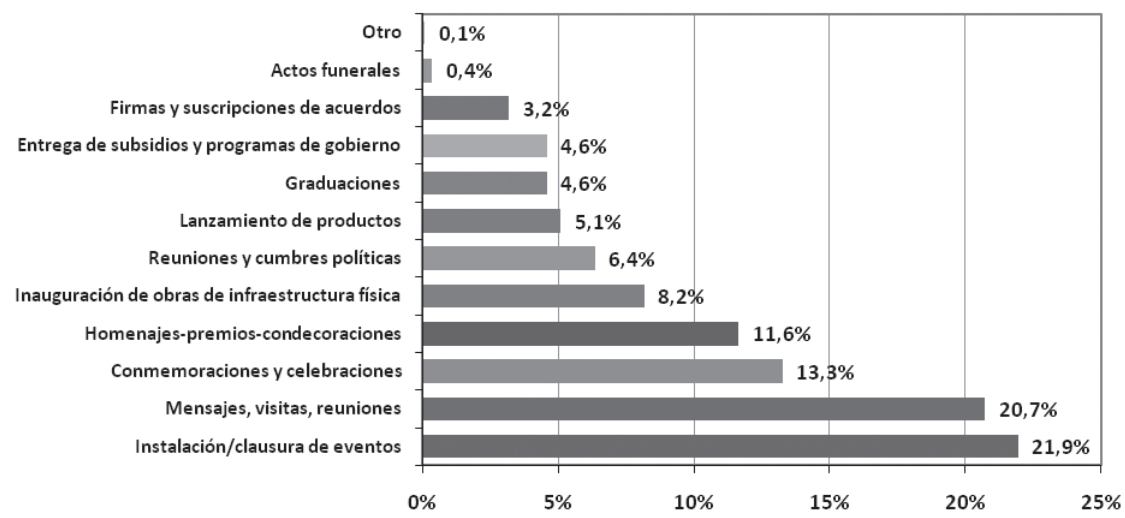

Fuente: Elaboración propia a partir del registro de los 1.982 discursos presidenciales pronunciados por Álvaro Uribe entre 2002-2010

En cuanto a los discursos presidenciales, si bien éstos interpelaban a públicos diferenciados, priorizaban en todo caso a los ciudadanos de la Nación, ya sean "organizaciones de la sociedad" (gremios de la producción, empresarios, asociaciones profesionales, centros de educación, medios de comunicación, comunidades culturales, entre otros), "sujetos sociales-colombianos en general" (habitantes de municipios, víctimas de violencias y tragedias, públicos del arte, el entretenimiento, el deporte, la educación y la cultura), o "beneficiarios de programas". Por tanto, era la tríada "empresarios + asociaciones + colombianos en general" los destinatarios privilegiados de la narrativa presidencial. 
Gráfico 2

Los públicos de los discursos presidenciales de Álvaro Uribe, 2002-2010



Fuente: Elaboración propia a partir del registro de los 1982 discursos presidenciales pronunciados por Álvaro Uribe entre 2002 y 2010

Los discursos presidenciales se centran en la coherencia con el relato propuesto: en la tríada seguridad democrática, confianza inversionista y cohesión social. Incluían temas de economía e infraestructura y de administración pública en tanto escenarios propicios para generar la "confianza inversionista". Los asuntos de la "seguridad democrática" (a través de acciones y resultados contra el crimen organizado, el terrorismo y el narcotráfico) fueron primordiales. Finalmente primó la idea de Nación, en tanto que una comunidad vinculada por la tradición, la cultura y los valores, por una parte, y la política social por la otra ("cohesión social"). 


\section{Gráfico 3}

Los asuntos ${ }^{28}$ de los discursos presidenciales de Álvaro Uribe, 2002-2010

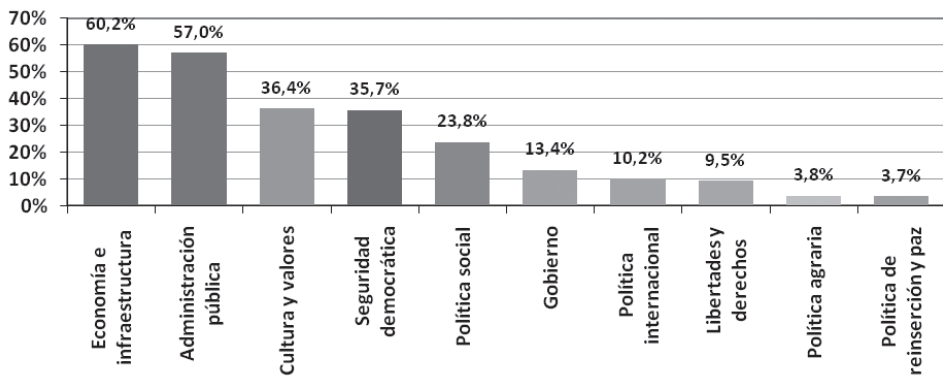

Fuente: Elaboración propia a partir del registro de los 1982 discursos presidenciales pronunciados por Álvaro Uribe entre 2002 y 2010

Así, Uribe estableció un "contrato de escucha" con la Nación colombiana a través del uso constante de los medios de comunicación y de la reiteración permanente de su discurso en distintos escenarios mediáticos y no mediáticos. En este sentido, produjo un efecto de agenda setting basado en la redundancia de un mensaje tantas veces repetido (seguridad democrática + confianza inversionista

28 Para este gráfico no se realizó una medición de la frecuencia de cada asunto con respecto a los demás (lo que sumaría un 100\%) sino de la frecuencia de aparición de un asunto en el conjunto de discursos de Álvaro Uribe, lo cual explica por qué la suma general supera el 100\%. Por tanto, la lectura de cada porcentaje es así: el asunto "economía e infraestructura" apareció en el 60,2\% de los discursos de Uribe; esto es diferente a decir que el $60,2 \%$ de los discursos de Uribe tratan sobre "economía e infraestructura". En el primer caso consideramos más de un asunto por discurso (ésta es nuestra perspectiva), mientras que en el segundo asumiríamos que sólo existe un asunto en cada discurso. Así, "economía e infraestructura" afloró en el 60,2\% de los discursos presidenciales y hubiera podido llegar al $100 \%$ si Uribe la hubiese aludido en todos sus discursos. 
+ cohesión social). Como en un libreto con variaciones mínimas, repetía su mensaje comenzando en un sitio (en una entrevista de radio, en un discurso en la instalación de un evento, en la inauguración de una obra de infraestructura, en la entrega de algún subsidio gubernamental); seguía en otro lugar (en otra entrevista en otra emisora de radio, en otro discurso en otro evento, en otra inauguración, en otra ciudad del país); finalmente, su discurso terminaba resonando en los demás medios que terminaban hablando de lo mismo, con lo cual el Presidente y su equipo de Gobierno aseguraban una gran penetración de su mensaje.

En cuanto a los 276 consejos comunales, habría que afirmar que Uribe capturó la atención de sus gobernados, siempre mostrándose cercano y dispuesto a brindar soluciones a las inquietudes que exponían los asistentes. Para María Jimena Duzán, ${ }^{29}$ periodista y columnista, "todo esto no era más que un show mediático". No era un espacio donde la comunidad podía expresarse y hablar con el Presidente. Era un sitio donde el Presidente podía expresarse y mostrar ante los medios que era un Presidente preocupado por la comunidad. Una comunidad, en su mayoría sumisa y uribista, que a su vez no podía hablar mucho. Duzán recuerda el caso del alcalde de El Roble, Sucre, Eudaldo Díaz Salgado. En el Consejo Comunal número 17, del 1 de febrero de 2003, ${ }^{30}$ Díaz declaró que tenía amenazas contra su vida, con la idea de que el Gobierno tomara cartas sobre el asunto. Un mes después apareció asesinado. Tras este evento, el equipo de Gobierno vigiló con más detenimiento a los que ingresaban a las reuniones comunitarias con el Presidente, y así se cuidaba de que

29 Entrevista realizada en agosto de 2011.

30 Sobre este caso véase: Eudaldo Díaz. El costo de la verdad, en: http:// www.youtube.com/watch?v=uGBgifbbFQs; http://www.youtube.com/ watch?v=8xrBcjV0AyI\&NR=1 Recuperado el 6 de diciembre de 2011. 
no volviera a suceder algo similar otra vez. El disenso no existía, la propaganda sí.

Cada consejo comunal de gobierno era una puesta en escena donde Uribe encarnaba al presentador de televisión y los asistentes devenían escenografía y feligreses. Allí Uribe se despojaba de su rol de Presidente y se convertía en presentador, maestro de ceremonias y moderador: conducía el programa, daba la palabra, ofrecía soluciones y delegaba responsabilidades. Gobierno en vivo y en directo (Rincón, 2005; Castro, 2009). El televidente-pueblo sentía que el entretenedor-celebrity Uribe lo estaba teniendo en cuenta y le solucionaba sus problemas. Soluciones mágicas aparecieron para los problemas planteados. No importaba que la solución real nunca llegara; simbólicamente el problema estaba resuelto.

Un Presidente que gobierna ocho años, con una imagen de favorabilidad popular superior al $60 \%$, demuestra que su estrategia y actuación de comunicación fue bastante efectiva. La periodista Luz María Sierra (2011) resume estas estrategias en tres puntos fundamentales:

1. Uribe era quien diseñaba las estrategias esenciales: "Estaba todo el tiempo pensando, definiendo. El maduraba mucho lo que iba a decir" (Jaime Bermúdez, citado por Sierra, 2011: 43).

2. Todos los días los asesores en comunicación (Bermúdez y Galán) se reunían con el Presidente, incluidos sábados y domingos, a las 7 de la mañana, así fuera por teléfono.

3. Uribe tomaba las decisiones a partir de las encuestas con el fin de controlar sus propuestas. "Jaime Bermúdez medía la opinión pública todo el tiempo. Teníamos encuestas, medíamos la reacción de la gente a los temas críticos, a los pronunciamientos, al desempeño de los ministros. Eso lo hacíamos semanal, quincenal, mensual. Hacíamos preguntas textuales."(Ricardo Galán, 
citado por Sierra, 2011: 43). Si alguna medida de su Gobierno no resultaba popular, él insistía pero dejaba de alardear al respecto, como en el caso del pago a los informantes o de la negación del acuerdo humanitario.

Podría decirse entonces que la comunicación política de Álvaro Uribe se caracterizó por el quiebre de la figura del Presidente distante, del gobernante lejano, del político al servicio de los medios. A diferencia de las prácticas políticas de la élite tradicional bogotana (o hecha a la medida bogotana), a Uribe le gustaba untarse de pueblo. Le añadía además el "efecto de intimidad": para poder identificarse plenamente con los colombianos se documentaba mañana, tarde y noche en la televisión. Pero también le añadía pequeños gestos de cercanía y de afecto, tales como llamar por su nombre de pila a su interlocutor, darle su número telefónico, preguntarle por la familia y su comunidad. La suya era una relación parasocial, íntima con el "compatriota", lo cual permitía que el ciudadano pasara del anonimato a hacerse visible ante el Presidente. De esta manera, el Presidente iba construyendo la imagen del "presidente amigo" que sí se podía tocar.

Pero la paradoja es que el de Uribe era un acercamiento a medias. A modo de hipótesis, era la gente, no el pueblo, el sujeto construido por Uribe; era la patria, no el pueblo, el sujeto interpelado. En Uribe había más patria que pueblo. Su discurso tenía como destinatario al pueblo, pero sólo en el plano de lo comunicativo; en lo político y económico, al proyecto uribista poco le interesó integrar a los sectores más subordinados, marginados y pobres del país a formas universales de ciudadanía, de seguridad social y de leyes laborales, por ejemplo. Su Gobierno no rompió con la élite política colombiana, ni destruyó el "viejo orden" de las exclusiones y desigualdades de diverso tipo (Dugas, 2003; Galindo, 2007). El suyo seguía siendo 
el "viejo orden", pero esta vez apoyado en una renovada "política del contacto" que lo acercó a las personas, lo volvió más íntimo, más humano, pero a la vez lo alejó de las grandes transformaciones del país. El pueblo producido por la retórica asistencialista de Uribe no pasó del nivel de ser receptor-beneficiario de programas: no lo incluyó en la sociedad, sino que lo mantuvo como espectador del espectáculo de la democracia.

Uribe triunfó en los corazones de los colombianos al convertir su actuación comunicativa en verdad política, esto es, al ganar la batalla por el "sentido común" en torno a un consenso de derechas que supo articular los temores, las incertidumbres y las expectativas de amplios sectores del país bajo el paraguas que interrogaba " $i$ sabe usted de qué lado está?" La suya fue, por tanto, una narrativa que cabalgó sobre los tropos de una cultura popular (familia, religión, tradición, control del sexo y violencia), eficaz en la producción colectiva de una oferta nacional de símbolos, retóricas y gestos: "Al que madruga Dios le ayuda"; "a la gente hay que decirle las cosas en la cara"; "que mande bien o mal, pero que mande" (dichos que pronunciaba recurrentemente en sus discursos). No le interesaba generar espacios para la participación activa de interlocutores políticos con puntos de vista diferentes, sino producir sujetos sociales que, antes de disentir, debían obedecer; el que obedecía quedaba incluido en el estado del bienestar.

\section{El manual de estilo de la comunicación al estilo Uribe}

Para terminar queremos dejar en evidencia cuáles serían los criterios comunicativos que convirtieron a Uribe en un gobernante exitoso en los índices de favorabilidad política. 
1. Para la comunicación de éxito político se requiere de una celebridad que sea auténtica y entretenida en el horizonte de lo popular-mediático: Uribe lo era. "Tiene claro a dónde quiere llevar el país y lo comunica bien".

2. Para la comunicación de éxito político se debe tener un relato claro y contundente para comunicar, que a su vez sea compartido por la sociedad: Uribe prometió un país feliz sin las FARC (seguridad), con empleo (confianza inversionista) y cercano a las necesidades de la gente (subsidios).

3. Para la comunicación de éxito político es necesario tener en claro quién es el enemigo, definir el gesto del enfrentamiento. Uribe la localizó en las FARC y desde ahí dividió al país en terroristas y patriotas: “¿Sabe usted de qué lado está?"

4. Para la comunicación de éxito político se debe actuar el relato en las lógicas populares y mediáticas, y Uribe lo hizo. Él era rural, religioso, familiar, tradicional, líder, motivador, vengativo, autoritario amoroso.

5. Para la comunicación de éxito político se debe hablar, actuar, soñar como el pueblo. Y es que el pueblo es una forma de gobernar, no una ideología. ${ }^{31}$ Uribe era el lenguaje del pueblo: meloso, caritativo, paternal, vengativo con los ricos, rural, trabajador, católico y amante de su patria.

6. Para la comunicación de éxito político se debe tener en claro cómo interpelan los medios de comunicación: la televisión para el gesto, la radio para la cercanía, la prensa para la agenda, las redes para los seguidores. Uribe lo hizo así.

Su estrategia se adapta a la propuesta teórica de Ernesto Laclau. Fue un populista que logró consolidar esas demandas bajo la figura de un enemigo común. De esta manera su ideología carecía de cualquier contenido específico (Laclau, 2006). 
7. Para el éxito político se debe siempre tener la iniciativa de agenda pública. Uribe lo hacía poniendo los temas, evadiendo las preguntas, asumiendo la acción frente a las críticas, nunca escondiéndose del gesto público.

8. Para la comunicación de éxito político toda acción de gobierno se debe convertir en un símbolo. Uribe convirtió una carretera, un soldado, una casa, una vestimenta, una palabra, un consejo comunitario y un discurso en símbolos-mitos que comunicaban el éxito de una política.

9. Para la comunicación de éxito político se requiere de estrategias de persuasión y mercadeo. No hay que inventar nada: sólo la autenticidad del líder. Uribe fue una celebridad mediática y un motivador auténtico que además construyó liderazgo, confianza y credibilidad. Se mantuvo en campaña permanente, se apoyaba en cifras, hablaba en el lenguaje de las mayorías, explotaba las pasiones del oyente, no se cansaba de repetir el relato, ponía la cara en las crisis y medía permanentemente la opinión pública.

10. Para la comunicación de éxito político hay más patria que pueblo. Uribe hablaba, actuaba y era el pueblo, pero el gran objetivo era la patria: algo más allá de cada uno. En nombre de ese abstracto, el pueblo se debe sacrificar.

Duranto ocho años, Álvaro Uribe fue la historia con más amor y rating en el corazón de los colombianos. Hoy en día lo sigue siendo como opositor al Gobierno de su heredero Juan Manuel Santos (2010-2014), porque actuó bajo un relato claro y consistente e hizo verosímil un personaje misional: el refundador de una Nación. 


\section{Referencias bibliográficas y Fuentes}

\section{Entrevistas realizadas para el informe}

Padilla, Nelson Fredy, editor del domingo del diario $E l$ Espectador

Gutiérrez, Élber, editor político del diario El Espectador Arango, Rodolfo, filósofo, profesor de la Universidad de los Andes, columnista de El Espectador

Botero, Felipe, politólogo, profesor de la Universidad de los Andes

Duzán, María Jimena, periodista y columnista de la revista Semana

Forero Tascón, Álvaro, analista político y columnista de El Espectador

Samper, María Elvira, periodista y ex editora de la revista Cambio

\section{Referencias bibliográficas}

Aristóteles (1994, [siglo IV a. C.]), Retórica, Madrid, Gredos. Arroyo, Luis (2012), El poder político en escena, Madrid, RBA libros.

Bermúdez, Jaime (1999), Battles for public opinion: mass media, political scandal and presidential popularity in Colombia (1994-1996) and Venezuela (1989-1993), tesis de doctorado, Universidad de Oxford.

Bobbio, Norberto y Nicola Matteucci (1982), Diccionario de política, México, Siglo XXI.

Bonilla, Jorge Iván (2004), "El consenso por otras vías. Medios de comunicación, opinión pública y conflicto armado en Colombia”, en Luis A. Restrepo (coord.), Síntesis Colombia, 2002-2003, Bogotá, IEPRI, FESCOL, Nueva Sociedad, pp. 9-30.

Castro, Luisa Fernanda (2009), Análisis del discurso político de Álvaro Uribe Vélez, en los consejos comunitarios 
del período 2002-2006, desde un marco neopopulista, monografía de grado, Bogotá, Universidad del Rosario. De la Torre, Cristina (2005), Uribe o el neopopulismo en Colombia, Medellín, La carreta.

Domenach, Jean (1963), La propaganda política, Buenos Aires, Eudeba.

Dugas, John (2003), "The emergence of Neopopulism in Colombia? The case of Álvaro Uribe", Third World Quarterly, vol. 24, núm. 6, pp. 1117-1136.

Escudero, Lucrecia (2002), "Un sujeto patémico: los desaparecidos en la prensa argentina”, en DeSignis, 2, pp. 187-201. Galindo, Carolina (2007), "Neopopulismo en Colombia: el caso del gobierno de Álvaro Uribe Vélez", Íconos, 27, pp. 147-162. Recuperado el 24 octubre de 2011 de www.flacso.org.ec/docs/i27galindo.pdf.

García, Virginia, Orlando D’Adamo y Gabriel Slavinsky (2005), Comunicación Política y campañas electorales, Buenos Aires, Gedisa.

García, Miguel y Laura Wills (2011), "El poder de la televisión. Medios de comunicación y aprobación presidencial en Colombia", en Angélica Rettberg y Omar Rincón (eds.), Medios, democracia y poder, Bogotá, Ediciones Uniandes, pp. 135-158.

Gergen, David (2000), Eyewitness to power, New York, Touchstone.

González, Fernán (2003), “¿Colapso parcial o presencia diferenciada del Estado en Colombia?", Colombia internacional, 58, pp. 124-157. Recuperado el 24 de octubre de 2011 de http://colombiainternacional.uniandes. edu.co/view.php/422/view.php

González, María Fernanda (2013), "Del uribismo popular al santismo elitista", El Espectador, 24 de noviembre. Recuperado el 1 de diciembre de 2013 de http://www. elespectador.com/noticias/politica/del-uribismo-popular-al-santismo-elitista-articulo-460166 
Hovland, Carl, Irving Janis y Harold Kelley (1953), Communication and persuasion. Psychological studies of opinion change, New Haven, Yale University Press. Laclau, Ernesto (2006), La razón populista, México, Fondo de Cultura Económica.

Maarek, Philippe (1996), Marketing político y comunicación, Buenos Aires, Paidós.

Merton, Robert (1992 [1949]), "Estudios sobre la propaganda por radio y cinematógrafo", en Robert Merton, Teoría y estructura social, México, Fondo de Cultura Económica, pp. 595-614.

Montoya, Catalina (2007), El presidente Álvaro Uribe y la nueva dramaturgia política (el presidente construido y narrado en los noticieros de televisión), tesis de maestría, Medellín, Instituto de Estudios Políticos, Universidad de Antioquia. Recuperado el 6 de diciembre de 2011 de http://bibliotecavirtual.clacso.org.ar/ ar/libros/colombia/iep/tesis/montoya/

Morris, Dick (1999), The New Prince, New York, St. Martin's Press.

Pecaut, Daniel (2003), Midiendo fuerzas. Balance del primer año del gobierno de Álvaro Uribe Vélez, Bogotá, Planeta.

Perea, Carlos Mario (1996), Porque la sangre es espiritu. Imaginario y discurso político en las elites capitalinas, 1942-1949, Bogotá, IEPRI-Aguilar.

Rincón, Omar (2002), “La televisación de la política (Uribe: ¿una producción de la realidad o una historia de ficción?)", Revista Foro, 45, pp. 38-49.

-—(2005), "Uribe tevé: cuando gobernares una emoción televisiva", Número, 46, pp. 10-21. Recuperado el 6 de diciembre de 2011 de http://www.revistanumero. com/46/uribe.htm

_-(2008), "De celebrities pero motivadores pero telepresidentes pero... ¿ idemocracia?", en Omar Rincón 
(ed.), Los telepresidentes: cerca del pueblo y lejos de la democracia, Bogotá, C3/FES, pp. 149-171.

_-(2013), "Melo-política: de la comunicación sin ideología o la política como telenovela”, en Ismael Crespo y Javier del Rey, Comunicación política \& campañas electorales en América Latina, Madrid, Biblos.

Sierra, Luz María (2011), Álvaro Uribe: Un presidente de teflón. La estrategia de opinión pública que lo hizo inmune a la crisis, tesis de maestría, Bogotá, Universidad de los Andes. 